\title{
ECTOPIC HIGH ORIGIN OF A CORONARY ARTERY FROM THE AORTA - A POSSIBLE CAUSE OF SUDDEN DEATH
}

\author{
Bülent Eren ${ }^{1}$, Nursel Türkmen ${ }^{2}$, Berna Senel ${ }^{3}$ \\ Council of Forensic Medicine of Turkey, Bursa Morgue Department ${ }^{1}$; Uludag University Medical Faculty, Forensic \\ Medicine Department, Council of Forensic Medicine of Turkey, Bursa Morgue Department ${ }^{2}$; Council of Forensic \\ Medicine of Turkey Istanbul, Morgue Department ${ }^{3}$
}

Summary: Congenital anomalies originating it the coronary arteries are of special interest for forensic specialists. The presented case is a man found dead on the Coast of Marmara Sea. The death was considered to be suspicious and an autopsy was performed. On the macroscopic autopsy, the ostium of the right coronary artery was hole-like, located in a normal position, but the ostium of the left coronary artery was pocket-shaped and located in the left wall of the ascending aorta and above the rim of the sinotubular junction. We describe an asymptomatic, but didactic case with ectopic high origin of the left coronary artery.

Key words: Ectopic coronary; Death; Forensic autopsy

\section{Introduction}

A congenital origin of coronary artery anomalies are of special interest for forensic specialists because anomalous origins of the coronary arteries often increase the risk of sudden death $(1,2,3,4,5,6,8,9)$. Ectopic high origin of coronary arteries has been defined as having ostia originating above the supravalvular ridge-sinotubular junction (1-4). We report here is an asymptomatic but interesting case of sudden death with ectopic high origin of the left coronary artery.

\section{Case report}

The death certificate showed that the victim was found dead on the coast of the Marmara Sea after a boating accident while fishing with friends. The death was considered to be suspicious by the prosecutor and an autopsy was mandated. The case was a 51-year-old cadaver; he was $168 \mathrm{~cm}$ tall and weighed $90 \mathrm{~kg}$. Family members and friends explained that he was a healthy individual and he had never been medically treated. On inspection, there were no specific traumatic findings. Macroscopic and microscopic examination of both lungs showed intensive edema; the right lung weighed $960 \mathrm{~g}$, left lung weighed $790 \mathrm{gr}$. The pericardium was normal in dissection; the heart weighed $430 \mathrm{~g}$, grossly normal in appearance. The ostium of the right coronary artery was hole-like, located in a normal position (Fig. 1). The ostium of the left coronary artery was pocketshaped with a diameter of $8 \mathrm{~mm}$ located in the high origin of the left wall of the ascending aorta $18 \mathrm{~mm}$ above the rim of the sinotubular junction, originating at a $45^{\circ}$ angle, coursing left and downward as far as its division in the two large branches. Ten sections from the heart were evaluated; histopathological investigation revealed no findings of acute and chronic myocardial ischemia, only mild hypertrophy was observed. Blood, urine and organ specimen analysis revealed none of the substances screened for in systematic toxicological methods. Death was reported as accidental drowning. Investigation of coronary artery anomalies in autopsies is of great importance for understanding sudden death cases from a medicolegal aspect.

\section{Discussion}

Anomalies originating in the coronary arteries are of special interest for forensic specialists because some of them may cause heart disease in patients and increase the risk of sudden death during exertion and normal activities (1-9). Ectopic high origin of coronary arteries has been defined as having ostium originating more than $5 \mathrm{~mm}$ above the supravalvular ridge $(3,4)$, or $10 \mathrm{~mm}$ above the sinotubular junction $(1,2)$. In our case, the left coronary artery ostium was pocket-shaped with a diameter of $8 \mathrm{~mm}$ at its largest and located in the left aortic wall of the ascending aorta $18 \mathrm{~mm}$ above the rim of the sinotubular junction originating at an acute $45^{\circ}$ angle, whereas the right artery was hole-like shaped and located in a normal position. Some authors have stated that an ectopic high location of the ostium of the coronary artery decreases the coronary perfu- 


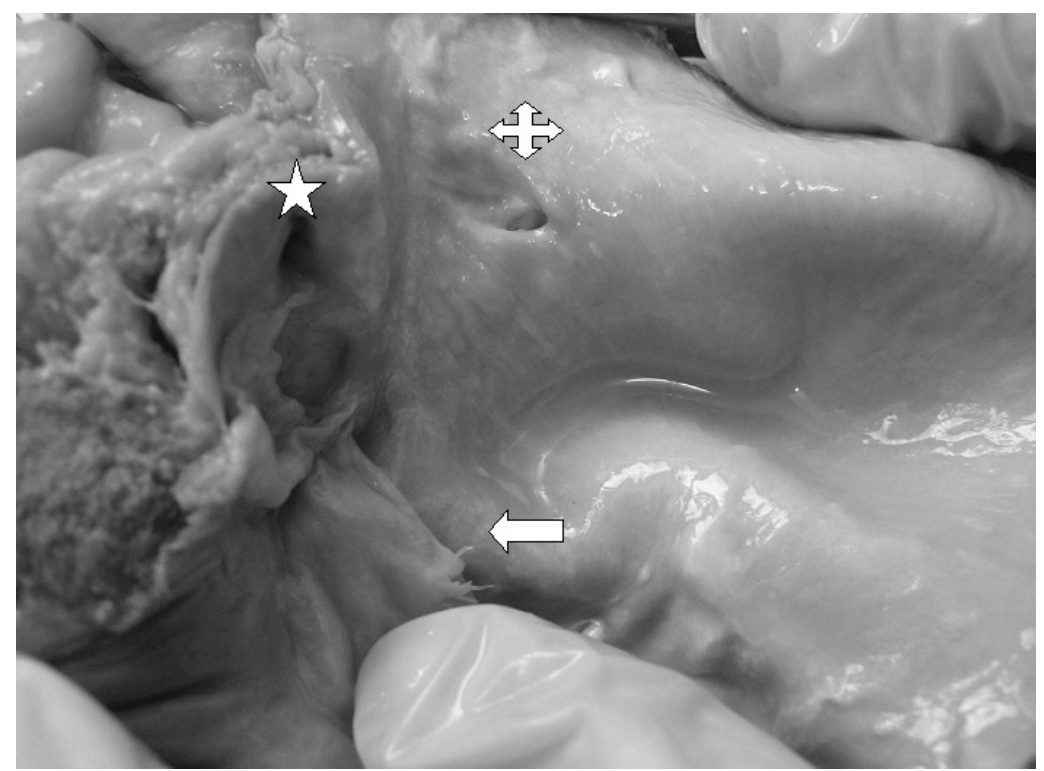

Fig. 1: A four-way arrow pointing the ostium of the left coronary artery, a star pointing to the ostium of the right coronary artery, an arrow pointing to the aortic valves.

sion, which on the other hand is also related to the angle at which the coronary artery leaves the aorta (4); in our case, however, there was no evidence of myocardial ischemia. The acute angle at which the anomalous artery leaves the aorta results in a fiap-like mechanism at the coronary ostium. Some authors have mentioned that in acute high ectopic origins of the coronary artery, increase in blood flow during exercise made the artery pull the upper border of the aortic wall, and push the lower border upward, resulting in transient flow impairment of the anomalous ectopic coronary artery $(2,3,6,9)$. In the described case the large diameter of the coronary ostium supplied sufficient myocardial perfusion, and in addition there was mild myocardial hypertrophy. The very high origin of the left coronary artery guides it on a course left and downward to where it divides into the two large branches. This can couse compression of the coronary artery in the passage between the aorta and right ventricular outflow, which has been mentioned as a probable cause for cardiac morbidity and mortality $(6,9)$.
On the other hand Roberts states that patients who survived childhood with anomalous left coronary arteries often had various symptoms such as angina, impaired left ventricular function, myocardial infarction and progressive fatal heart failure.

The same author claims also that anomalous origin and passage of the left coronary artery has been associated with sudden cardiac death during or shortly after exercise (7). Furthermore, this may explain the sudden death in the presented case as a consequence of the common fatal effects of anomalous ectopic coronary arteries and drowning. We described the case of a patient whose left coronary artery rose from the ascending aorta with high takeoff, but without former clinical signs and symptoms of heart disease. We diagnosed the pathology incidentally during the autopsy in a case of accidental drowning. Specification of coronary artery anomalies in autopsies is of great importance for the scientific definition and classification of ectopic coronary arteries and for the explanation of sudden cardiac death from a medicolegal aspect $(5,7,8)$.

\section{References}

1. Angelini P. Normal and anomalous coronary arteries: definitions and classification. Am Heart J 1989;117:418-34.

2. Lipsett J, Cohle SD, Berry PJ, Russell G, Byard RW. Anomalous coronary arteries: a multicenter pediatric autopsy study. Pediatr Pathol 1994;14:287-300.

3. Mahowald JM, Blieden LC, Coe JI, Edwards JE. Ectopic origin of a coronary artery from the aorta: sudden death in 3 of 23 patients. Chest 1986;89:668-72.

4. Menke DM, Waller BF, Pless JE. Hypoplastic coronary arteries and high takeoff position of the right coronary ostium: a fatal combination of congenital coronary artery anomalies in an amateur athlete. Chest 1985; 88:299-301.

5. Nerantzis CE, Marianou SK. Ectopic "high“ origin of both coronary arteries from the left aortic wall: anatomic and postmortem angiographic findings. Clin Anat. 2000;13:383-6.

6. Ness MJ, McManus BM. Anomalous right coronary artery origin in otherwise unexplained infant death. Arch Pathol Lab Med 1988; 112:626-9.

7. Roberts, W.C. Major anomalies of coronary arterial origin seen in adulthood. Am. Heart J., 1986; 111: 941-63.

8. Tarhan A, Kehlibar T, Yilmaz M, et al. Right coronary artery with high takeoff. Ann Thorac Surg. 2007;83:1867-9.

9. Taylor AJ, Rogan KM, Virmani R. Sudden cardiac death associated with isolated congenital coronary artery anomalies. J Am Coll Cardiol 1992;20:640-7.

Received: 02/02/2009.

Accepted in revised form: 30/11/2009.

\section{Corresponding author:}

Bülent Eren, M.D., Council of Forensic Medicine of Turkey, Bursa Morgue Department; 16010, Osmangazi, Bursa, Turkey; e-mail:bulenteren2000@yahoo.com. 